CASE REPORT

Volume 16 Supp 12021

DOl: 10.21315/aos2021.16.s1.13

ARTICLE INFO

Submitted: 02/03/2021

Accepted: 27/05/2021

Online: 22/09/2021

\section{Bone Augmentation in Extrusive Teeth Repositioned Using Bone Grafts}

\author{
Charissa Roderica Hoediono*, Ghita Hadi Hollanda \\ Nala Husada Dental Hospital, Universitas Hang Tuah Surabaya, \\ Kota Surabaya, fawa Timur 60117, Indonesia
}

*Corresponding author: charissa.rsgm@gmail.com

To cite this article: Hoediono CR, Hollanda GH (2021). Bone augmentation in extrusive teeth repositioned using bone grafts. Arch Orofac Sci, 16(Supp.1): 83-90. https://doi.org/10.21315/aos2021 $.16 . s 1.13$

To link to this article: https://doi.org/10.21315/aos2021.16.s1.13

\begin{abstract}
Extrusive luxation is a traumatic dental injury (TDI) due to the action of forces, especially in the oblique angle. Partial displacement of the tooth is one of its characteristics. Repositioning is the treatment of choice for this type of trauma. The mechanism of bone augmentation and splint in managing the post extrusive luxation teeth reposition was explored and reported. An 18-year-old male with a history of traffic accident which caused extrusive luxation of 11 and 21 with no alveolar bone fracture. The patient was managed by repositioning the teeth and applicating arch-bar on anterior maxillary teeth. After eight weeks of evaluation, periapical radiograph showed the distal bone of 21 had radiolucent appearance followed by Class 1 mobility. The arch-bar was removed, and the periosteal flap was made on the buccal side of 21 and the distal part was curetted then irrigated with $0.9 \%$ sodium chloride, then supplemented with bone graft material and pericardium membrane. Lastly, the flap was returned, the tooth was then stabilised using self-curing adhesive resin cement (Super-Bond). The tooth was kept under observation for two months. It was observed that the tooth was asymptomatic and still in function with no radiographic signs of pathosis. These results suggested that tooth reposition might be an alternative to prosthetic or implant dentistry. However, further human research is recommended with long standing follow-up periods and comparative studies to be carried out to identify whether dental implant replacement or reposition is the cost-effective treatment for extruded tooth.
\end{abstract}

Keywords: Bone augmentation; bone grafts; self-curing adhesive resin cement; Super-Bond; tooth reposition

\section{INTRODUCTION}

Traumatic injuries have become common public dental health problem which can occur anytime throughout life (Flores et al., 2007; Needleman, 2011). Trauma might involve both the hard and soft tissues (Ak et al., 2019). Traumatic injuries to the maxillary central incisor teeth in primary dentition commonly happen on the young adolescent populations with reported prevalence of up to $30 \%$ (York et al., 1978;
Andreasen et al., 2007; Cohenca et al., 2007a).

The status of periodontium can help to determine the success of treatment in traumatised teeth. However, treatment of traumatic injuries is quite complex and at times requires a multidisciplinary approach. Extrusive luxation is one of traumatic dental injury (TDI) usually caused by oblique forces. The clinical appearance shows partial displacement of the tooth out of its socket and also loosening of the periodontal spaces. 
Extrusive causes almost complete disruption of the periodontal ligament and the rupture of the apical neurovascular bundle (Cohenca et al., 2007b). Such dental injury leads to mild, moderate, or even severe mobility of the tooth and pulp circulation infarction (Amaral et al., 2017). The extrusive luxation is classified to three categories: extrusions smaller than or equal to $3 \mathrm{~mm}$ were considered mild, between $3 \mathrm{~mm}$ and $5 \mathrm{~mm}$ as moderate, and larger than $6 \mathrm{~mm}$ as severe. For severely extruded teeth and for those with closed apices, the risk of pulpal necrosis was the greatest (Humphreys et al., 2003).

The following are radiographs examination suggested by American Association of Endodontists (AAE) Guidelines (Diangelis et al., 2012; Ak et al., 2019): (1) Periapical radiograph with a $90^{\circ}$ horizontal angle with central beam through the tooth in question; (2) Occlusal view; (3) Periapical radiograph with lateral angulations from the mesial or distal aspect of the tooth in question; and (4) Cone-beam computerised tomography (CBCT).

Extrusive luxation trauma is ideally treated by an accurate clinical and radiographic examination. Next, it is followed by repositioning of the tooth in its socket, fixation of the affected tooth, and to be finished with occlusal adjustment and instructions to maintain the oral hygiene, the prognosis of the case, and follow-up schedule (Demir et al., 2007; Amaral et al., 2017).

\section{CASE SUMMARY}

\section{Subject}

An 18-year-old male was referred to the Nala Husada Dental Hospital, Surabaya, Indonesia, with history of traffic accident $6 \mathrm{~h}$ in prior which caused extrusive luxation of 11 and 21 . The intraoral clinical examination showed that both maxillary central incisors were $4 \mathrm{~mm}$ extruded relation to the place of origin (Fig. 1), presented grade III mobility and sensitivity to touch. Radiographically, (a)

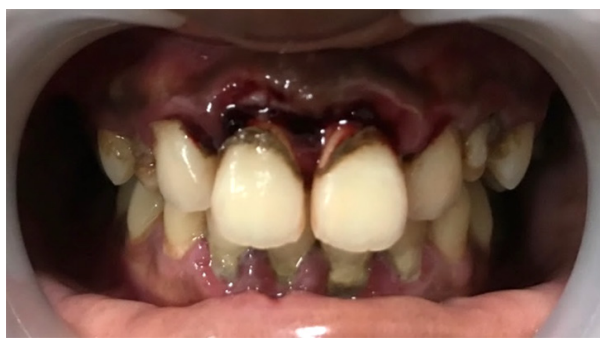

(b)

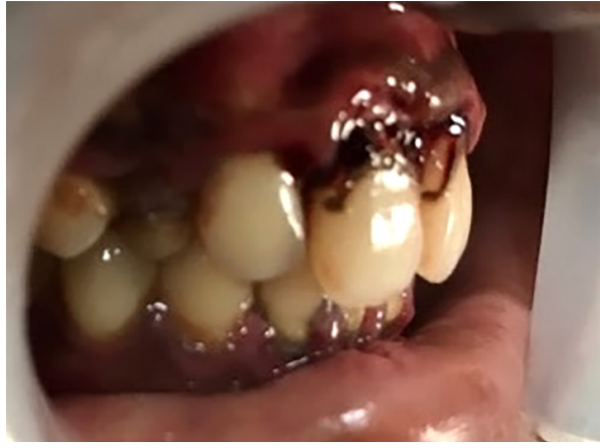

(c)

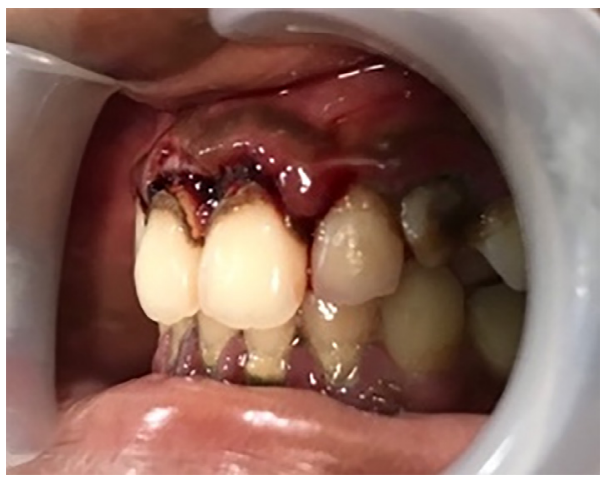

Fig 1. Initial intraoral picture showing the extrusion of the teeth 11, 21: (a) front side; (b) right side; and (c) left side.

it was observed that 11 and 21 had the periodontal ligament space increased in the periapical region and no alveolar bone fracture was visible (Fig. 2).

The patient was managed by repositioning the teeth carefully seeking alignment and avoiding excessive compression of the roots into their sockets. The occlusion was checked to prevent any traumatic interference. Care was taken without extracting the teeth and finished by applicating arch-bar on his anterior maxillary teeth. Amoxicillin $500 \mathrm{mg}$, every $8 \mathrm{~h}$ for 5 days, analgesic, and daily mouthwash with $0.2 \%$ chlorhexidine gluconate was prescribed. 


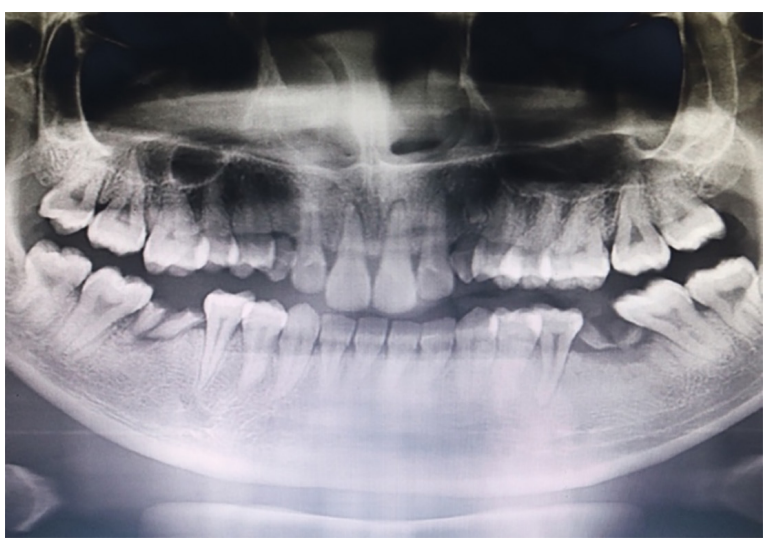

Fig 2. Initial panoramic radiograph, periapical region increased in the periodontal ligament space of the maxillary central incisor.

(a)

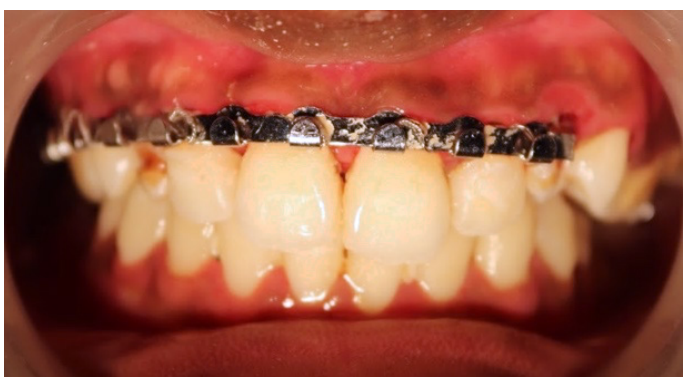

(b)

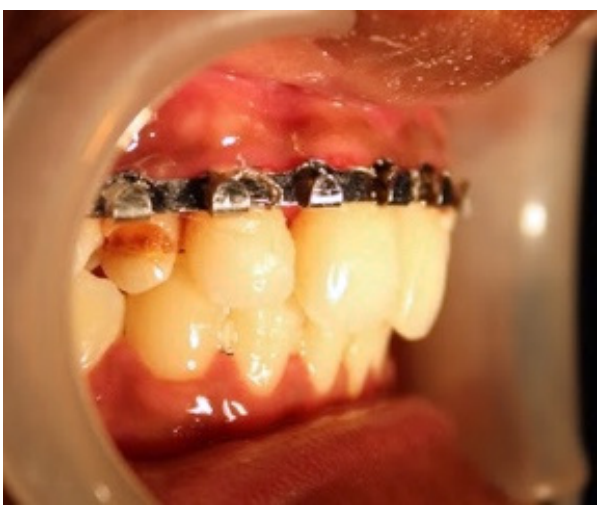

(c)

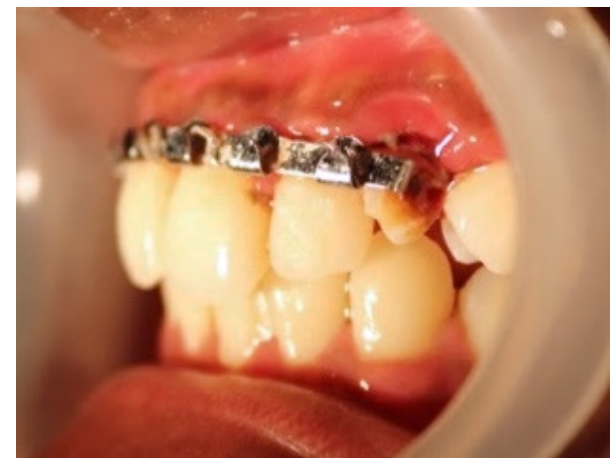

Fig 3. Intraoral picture at 8 weeks after treatment: (a) front side; (b) right side; and (c) left side.
The clinical and radiographic follow-up, 8 weeks after, showed the 11 did not present mobility, root resorption or associated pain. However, the 21 presented grade I mobility with $6 \mathrm{~mm}$ probing depth on the distal buccal of 21 (Fig. 3). Radiographically, the distal bone of 21 has radiolucent appearance with no associated pain (Fig. 4). After examining the diagnostic records, discussion, patient consultation and removing the archbar (Fig. 5), bone augmentation procedure was planned with the bone graft material and splint the teeth with self-curing adhesive resin cement (Super-Bond).

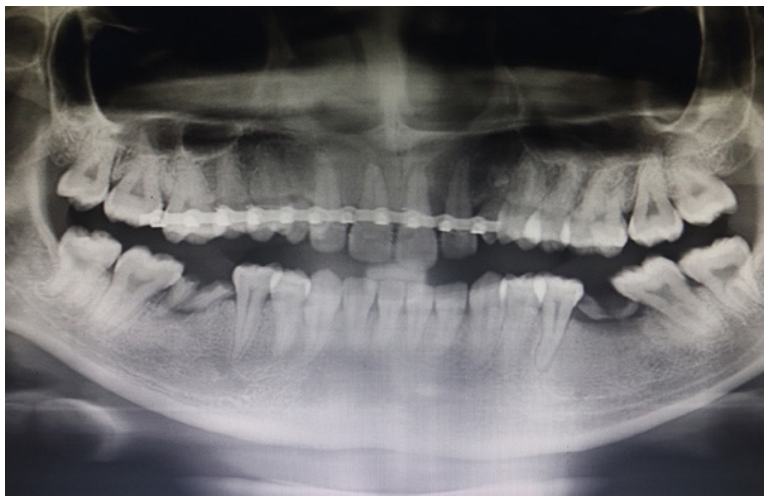

Fig 4. Panoramic radiograph at 8 weeks after treatment showing the integrity of the root surface and periodontal ligament space with bone defect on the distal area of 21 .

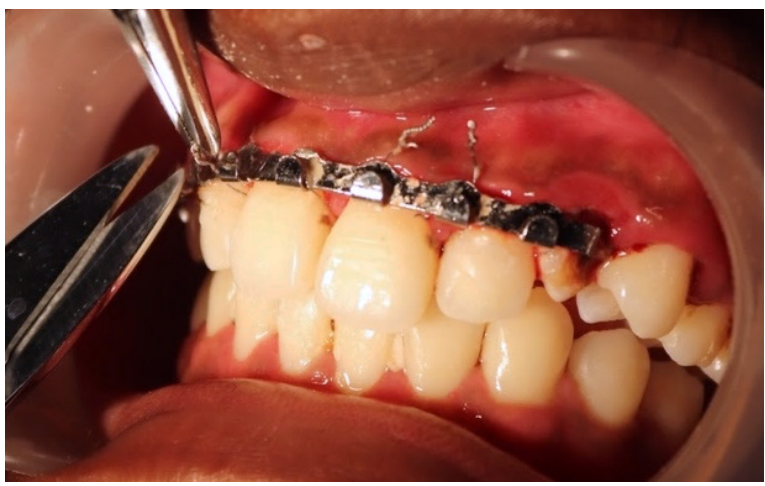

Fig 5. Removal of the arch-bar. 


\section{Case Management}

The presence of bony defects and the need of grafting was indicated. At the beginning, the patient was anesthetised with local anaesthesia in the maxilla and nerve block anaesthesia in the palatal incisory foramen (Fig. 6). After the arch-bar was taken off, the teeth were irrigated with $0.9 \%$ sodium chloride. After incision and elevating a mucoperiosteal flap (Fig. 7), bone defect was visible on the distal area of 21 (Fig. 8). The defect was then curetted and irrigated with saline until it was clean.

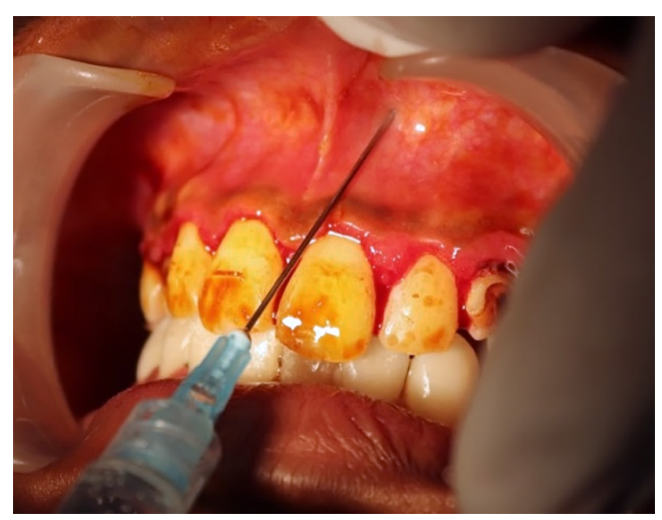

Fig 6. Local anaesthetic with infiltration technique.

(a)

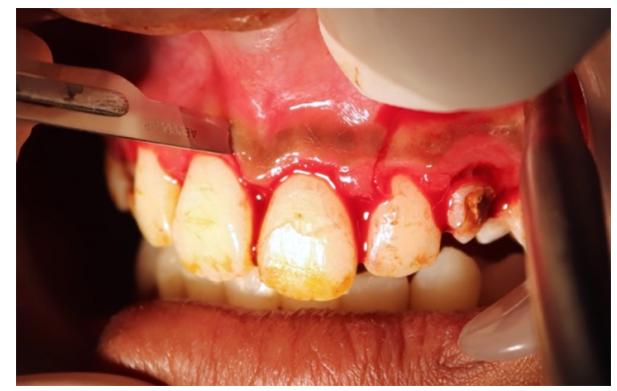

(b)

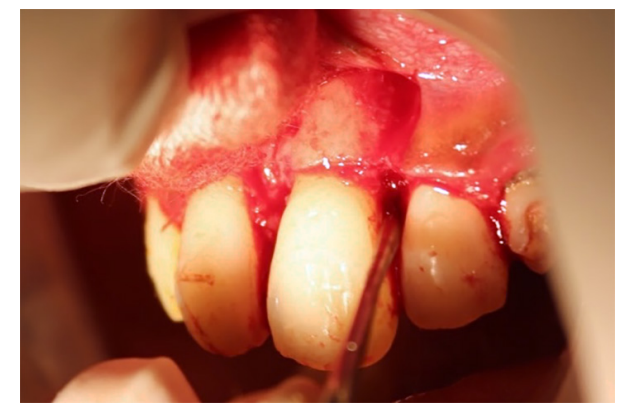

Fig 7. Incision and flap design: (a) incision; and (b) full thickness flap.
Bone graft was then placed gently inside the defect (Fig. 9). After bone graft reconstruction, the flaps are completely closed. Resorbable pericardium membrane was used to seal the bone graft in its place (Fig. 10). A synthetic 5.0 suture material with interrupted closure was done and the flap was returned (Fig. 11). Amoxicillin $500 \mathrm{mg}$, every $8 \mathrm{~h}$ for 5 days, analgesic and daily mouthwash with $0.2 \%$ chlorhexidine gluconate was prescribed. The patient was instructed to be more caution against chewing or brushing the area for at least one or two weeks and should use antibacterial rinses during that period.

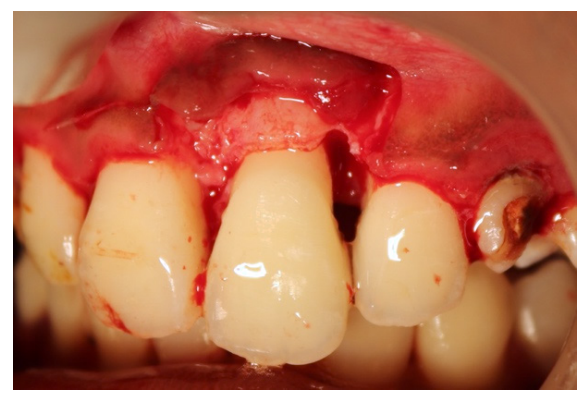

Fig 8. Bone defect on the distal buccal area of 21 .

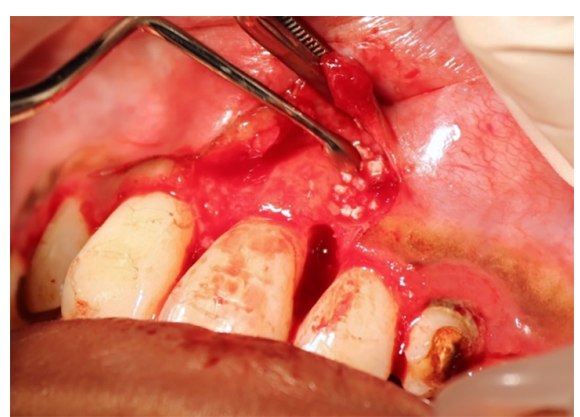

Fig 9. Filling the defect area with bone graft.

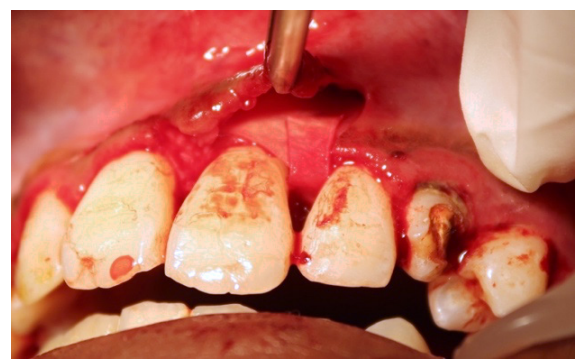

Fig 10. Secure the bone graft with pericardium membrane. 


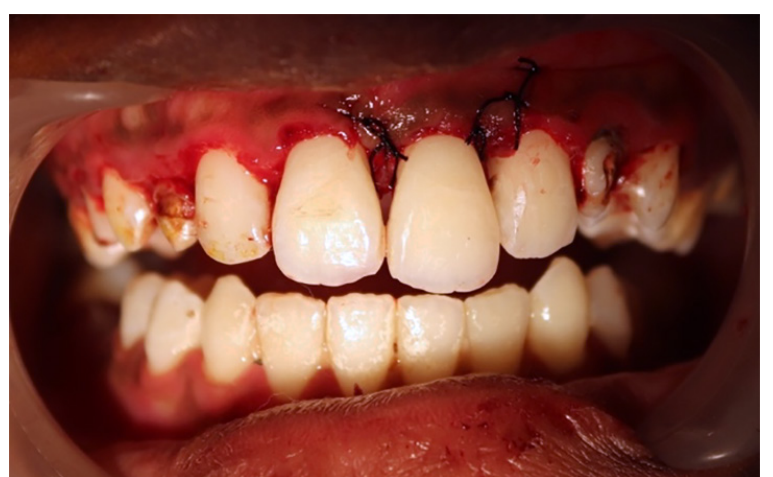

Fig 11. Returning the flap and sealed with sutures.

Super-Bond is a self-cure dental adhesive resin cement based in methyl methacrylate. It contains a high-performance bonding monomer, "4-META" (bonding monomer) and "TBB" (polymerisation catalyst). All surfaces to be bonded with Super-Bond must be properly prepared (surface preparation). We began by isolating the working area, then removing the contaminants and stains, rinsed thoroughly and dried. The appropriate etchant was applied directly from the syringe, waited for $30 \mathrm{sec}$ to $60 \mathrm{sec}$, then rinsed thoroughly with water and dried (Fig. 12).

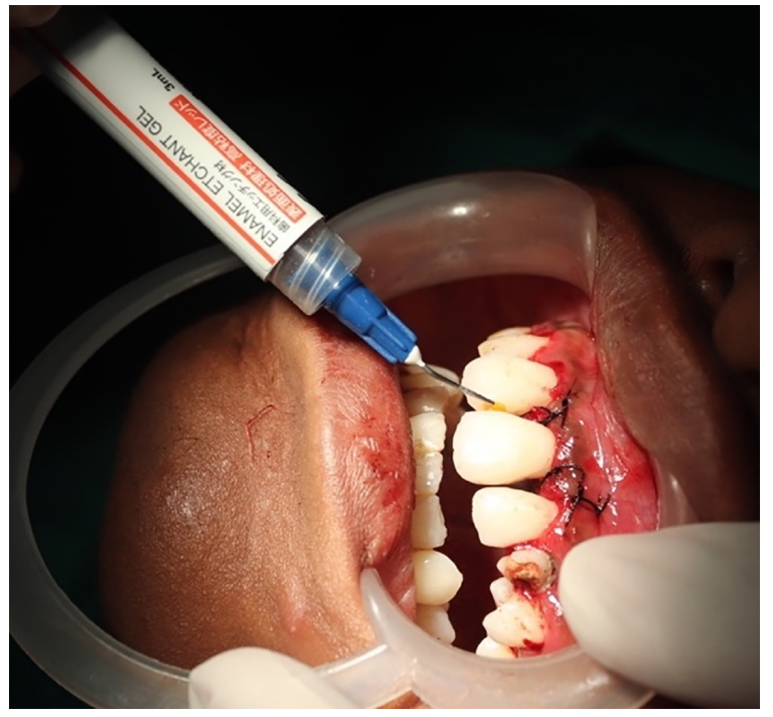

Fig 12. Enamel etching on the interdental area of $12,11,21,22$.
The mixing ratio of the monomer (base) to its catalyst is 4 to 1 . The catalyst syringe was held vertically and then a few drops of the liquid were added into the monomer. They were stirred steadily with a micro brush and the mixture was now an "activated liquid" (Fig. 13). Next, was the application of Super-Bond on the interdental area (Fig. 14); the brush was wetted with ample activated liquid as it was easier to make a ball form from the powder. Only a small ball of powder each time was used. A piece of gauze was used to clean the resin off the brush top before dipping it into the liquid again. Cotton pledget or a brush soaked with alcohol was used to remove as much excess resin as possible immediately. The hardened resin excess was removed with fine finishing bur (Fig. 15). The immediate result of the process was presented (Fig. 16).
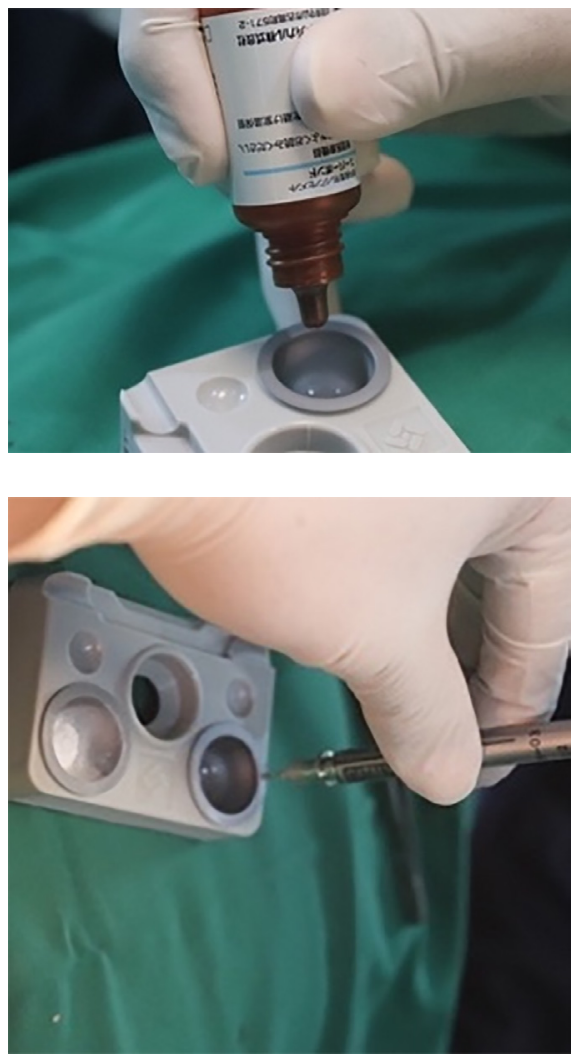

Fig 13. Mixing and activating the bonding (base dan catalyst). 


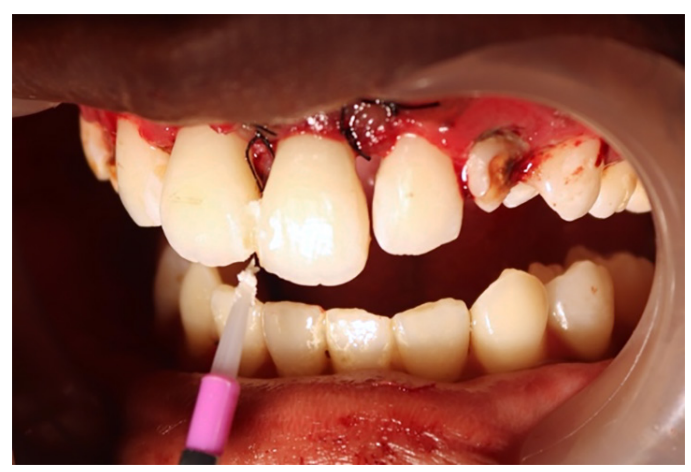

Fig 14. Application of self-curing adhesive resin cement (Super-Bond) on the interdental area.

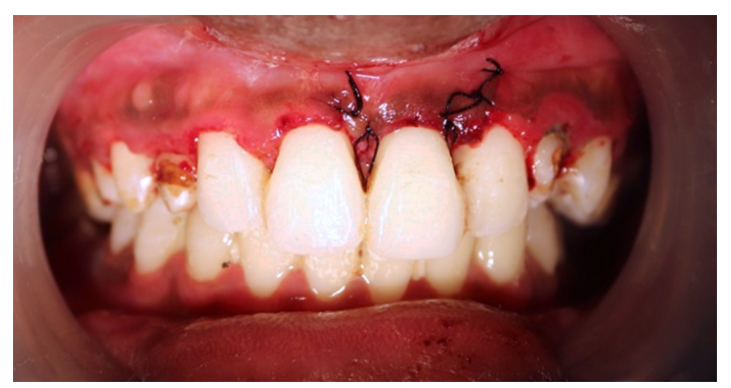

Fig 16. Immediate intraoral picture result.

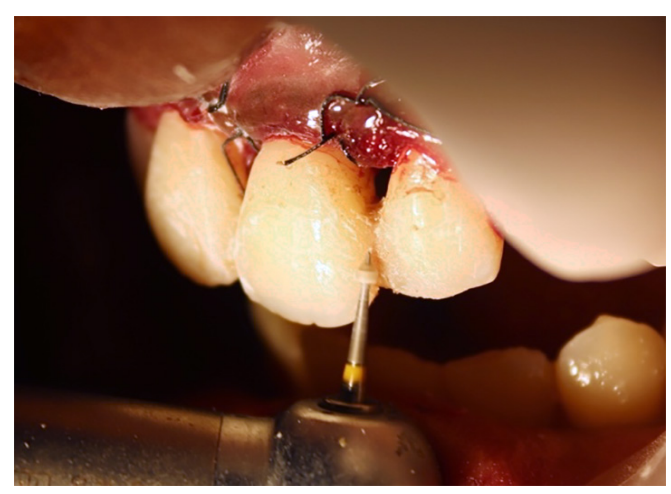

Fig 15. Smoothening the surface using the fine finishing bur.

\section{Post-Operative}

Seven days post-operative, the sutures were removed. The clinical findings demonstrated that the adopted clinical protocol was successful, as the tooth were asymptomatic and there was no gingival inflammation and mobility (Fig. 17). Satisfactory healing with no post-operative complications was observed after a 2-month follow-up (Fig. 18).

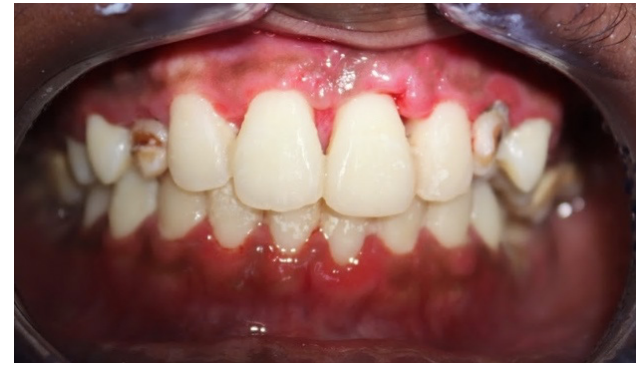

(a)

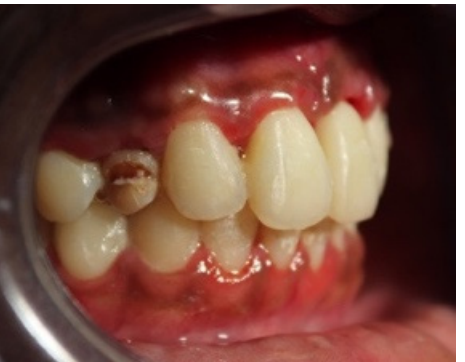

(b)

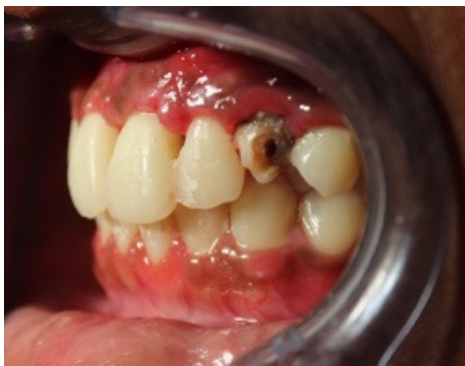

(c)

Fig 17. Intraoral picture at 1 week after bone augmentation treatment: (a) front side; (b) right side; and (c) left side.

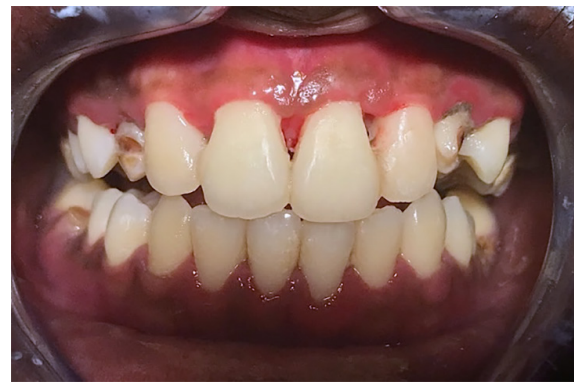

(a)

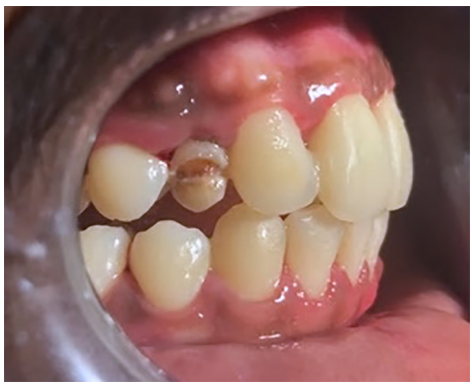

(b)

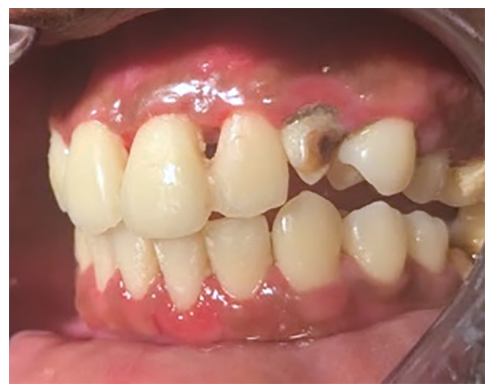

(c)

Fig 18. Intraoral picture at 2 months after bone augmentation treatment: (a) front side; (b) right side; and (c) left side. 


\section{DISCUSSION}

Extrusive luxation is one type of TDI caused by oblique action forces. Clinical appearance usually shows loosening and partial displacement of the tooth from its socket. An accurate clinical and radiographic examination, correctly repositioning the tooth to its socket, selecting semirigid fixation, occlusal adjustment and post operation instructions are the ideal treatment procedures, as was practiced in the present case (Amaral et al., 2017).

Before the extruded tooth is pushed to its socket, there is a need to eliminate the necrotic tissue and irrigate both the surrounding gingiva and the tooth. Some authors suggested that cleaning the root surface with soft pumice prophylaxis, while others recommended Hank's balanced salt solution, Ringer's lactate, milk, saline and saliva if the tooth was avulsed (Adnan et al., 2018). There were others who had suggested soaking the tooth in doxycycline $0.005 \%$ for $5 \mathrm{~min}$ before replantation and had shown $40 \%$ to $60 \%$ higher chance for pulp revascularisation (Ram \& Cohenca, 2004). In the present case, the teeth were irrigated with $0.9 \%$ sodium chloride and had satisfactory results.

Time is a critical factor in almost all traumatic situations for the successful treatment of extrusive luxations. Repositioning or even replanting a tooth must be done as early as possible. In the present case, unfortunately there was a failure in the formation of the callus in the distal buccal area of tooth 21 so that the connective tissue was more dominant, and the process of bone pooling could not proceed perfectly, resulted with defects. Therefore, bone augmentation was indicated. Suitable technique must be selected after careful evaluation of defected area and considering the related factors such as the extent of the defect, patient preference, surgeon expertise, available materials and instruments, cost, and ease of specific procedures to be performed.
The success rate of the bone augmentation treatment is determined by various factors. A good isolation is necessary to prevent contamination. A full mucoperiosteal flaps to get a reflection must be done and carefully handled on the traumatic soft tissues. To eliminate voids, the most suitable bone graft materials must be chosen. There is a need to control the bleeding with intraoral pressure dressing for $10 \mathrm{~min}$ to $15 \mathrm{~min}$. A good technique in suturing will keep the tissues intact. And lastly, clear postoperative instructions to the patient must be given (Callan, 1993). All techniques and available materials to enhance the proper selection of methods to obtain the best outcomes and the high success rates must be strategically reviewed. In the present case, the procedures chosen were simple, safe and effective for treatment of osseous defect, after the extrusive luxation teeth repositioning.

\section{CONCLUSION}

The outcomes in the present case suggested that tooth reposition might be an alternative to prosthetic or implant dentistry. However, further human research is recommended with long standing follow-up periods and comparative studies to be carried out to identify whether dental implant replacement or reposition is the cost-effective treatment for extruded tooth.

\section{ACKNOWLEDGEMENTS}

The authors would like to thank Nala Husada Dental Hospital for providing the facilities and support staff.

\section{REFERENCES}

Adnan S, Lone MM, Khan FR, Hussain SM, Nagi SE (2018). Which is the most recommended medium for the storage and transport of avulsed teeth? A systematic review. Dent Traumatol, 34(2): 59-70. https://doi.org/10.1111/edt.12382 
Ak AT, Ozdas DO, Zorlu S, Karataban PK (2019). Dental traumatology in pediatric dentistry. In: Gözler S (ed.), Trauma in Dentistry. London: IntechOpen Limited. https://doi.org/10.5772/intechopen.84150

Amaral MF, de Almeida MM, de Faria LP, Brandini DA, Poi WR, Okamoto R (2017). Treatment of extrusive luxation in permanent teeth: Literature review with systematic criteria. I Contemp Dent Pract, 18(3): 241-245.

Andreasen JO, Andreasen FM, Andersson L (2007). Textbook and Color Atlas of Traumatic Injuries to the Teeth, 4th edn. Copenhagen: Blackwell Munksgaard, pp. 224-225.

Callan DP (1993). Guided tissue regeneration without a stage 2 surgical procedure. Int $\mathcal{F}$ Periodontics Restorative Dent, 13(2): 173179.

Cohenca N, Simon JH, Mathur A, Malfax JM (2007a). Clinical indications for digital imaging in dento-alveolar trauma. Part 2: Root resorption. Dent Traumatol, 23(2): 105-113. https://doi.org/10.1111/j.1600 $-9657.2006 .00546 . x$

Cohenca N, Simon JH, Roges R, Morag Y, Malfaz JM (2007b). Clinical indications for digital imaging in dento-alveolar trauma. Part I: Traumatic injuries. Dent Traumatol, 23(2): 95-104. https://doi.org/10.1111/ j.1600-9657.2006.00509.x

Demir B, Demiralp B, Güncü GN, Uyanik MO, Cağlayan F (2007). Intentional replantation of a hopeless tooth with the combination of platelet rich plasma, bioactive glass graft material and non-resorbable membrane: A case report. Dent Traumatol, 23(3): 190-194. https://doi.org/10.1111/j.1600 $-9657.2005 .00414 . x$
Diangelis AJ, Andreasen JO, Ebeleseder KA, Kenny DJ, Trope M, Sigurdsson A et al. (2012). International Association of Dental Traumatology guidelines for the management of traumatic dental injuries: 1. Fractures and luxations of permanent teeth. Dent Traumatol, 28(1): 2-12. https://doi.org/10.1111/j.1600-9657.2011 $.01103 . \mathrm{x}$

Flores MT, Malmgren B, Andersson L, Andreasen JO, Bakland LK, Barnett F et al. (2007). Guidelines for the management of traumatic dental injuries. III. Primary teeth. Dent Traumatol, 23(4): 196-202. https://doi.org/10.1111/j.1600-9657.2007 $.00627 . \mathrm{x}$

Humphreys K, Al Badri S, Kinirons M, Welbury RR, Cole BO, Bryan RA et al. (2003). Factors affecting outcomes of traumatically extruded permanent teeth in children. Pediatr Dent, 25(5): 475-478.

Needleman HL (2011). The art and science of managing traumatic injuries to primary teeth. Dent Traumatol, 27(4): 295-299. https://doi.org/10.1111/j.1600 $-9657.2011 .01005 . x$

Ram D, Cohenca N (2004). Therapeutic protocols for avulsed permanent teeth: Review and clinical update. Pediatr Dent, 26(3): 251-255.

York AH, Hunter RM, Morton JG, Wells GM, Newton BJ (1978). Dental injuries in 11- to 13-year-old children. $N Z$ Dent F, 74(338): 218-220. 